\title{
Efficacy of Compound Danshen Dripping Pills combined with western medicine in the treatment of diabetic retinopathy: a systematic review and meta-analysis of randomized controlled trials
}

\author{
Hui Huang ${ }^{1 \#}$, Yuanyuan $\mathrm{Li}^{2 \#}$, Qun Huang ${ }^{1 \#}$, Ruxue Lei ${ }^{1}$, Weiwen Zou ${ }^{1}$, Yanlin Zheng ${ }^{1}$ \\ ${ }^{1}$ Department of Ophthalmology, Hospital of Chengdu University of Traditional Chinese Medicine, Chengdu, China; ${ }^{2}$ Department of \\ Ophthalmology, Xi'an Hospital of Traditional Chinese Medicine, Xi'an, China \\ Contributions: (I) Conception and design: All authors; (II) Administrative support: All authors; (III) Provision of study materials or patients: All \\ authors; (IV) Collection and assembly of data: All authors; (V) Data analysis and interpretation: All authors; (VI) Manuscript writing: All authors; (VII) \\ Final approval of manuscript: All authors. \\ \#These authors contributed equally as co-first authors. \\ Correspondence to: Yuanyuan Li. Department of Ophthalmology, Xi'an Hospital of Traditional Chinese Medicine, Xi'an 710001, China. \\ Email: liyuanyuan937@163.com.
}

Background The Compound Danshen Dripping Pills have been widely used in the treatment of diabetic retinopathy (DR), but there is a lack of systematic review of reports on this topic. To explore the efficacy of Compound Danshen Dripping Pills combined with western medicine in the treatment of diabetic retinopathy, we conducted a meta-analysis.

Methods: Randomized controlled trials published in the Chinese Medical Literature Database (CBM), Embase, PubMed, and Medline databases from January 2010 to August 2021 were searched. After screening the qualified literature, literature quality was evaluated by the Cochrane Handbook for Systematic Reviews of Interventions. Meta-analysis was performed on outcome measures including effective rate, visual field gray value, hemangioma volume, hemorrhagic plaque area, and visual acuity after diabetic retinopathy treatment with Compound Danshen Dripping Pills using Revman 5.3 analysis software to comprehensively evaluate the utility of Compound Danshen Dripping Pills.

Results: A total of 167 documents were preliminarily searched, and 8 studies involving 524 patients were included for meta-analysis. Meta-analysis showed that the statistical value of the effective rate of diabetic retinopathy treatment in the intervention group and control group was OR $=5.00,95 \%$ CI: $2.84,8.83$, $\mathrm{P}<0.0001$. The statistical value of visual field gray value comparison was $\mathrm{MD}=-0.93,95 \% \mathrm{CI}:-0.98,-0.89$, $\mathrm{P}<0.00001$. The statistical value of hemangioma volume was $\mathrm{MD}=-3.16,95 \% \mathrm{CI}:-3.48,-2.84, \mathrm{P}<0.00001$. The statistical value of hemorrhagic plaque area comparison was MD =-0.65, 95\% CI: $-0.97,-0.32$, $\mathrm{P}<0.0001$. The statistical value of visual acuity comparison was $\mathrm{MD}=0.15,95 \% \mathrm{CI}: 0.10,0.19, \mathrm{P}<0.00001$.

Discussion: The Compound Danshen Dripping Pills combined with western medicine are effective and safe in the treatment of diabetic retinopathy.

Keywords: The Compound Danshen Dripping Pills; diabetic retinopathy (DR); meta-analysis

Submitted Aug 23, 2021. Accepted for publication Sep 28, 2021.

doi: $10.21037 /$ apm-21-2563

View this article at: https://dx.doi.org/10.21037/apm-21-2563 


\section{Introduction}

Diabetic retinopathy (DR) is a common microvascular complication of diabetes which can cause visual impairment, and in severe cases, macular edema, retinal detachment, and vitreous hemorrhage, putting patients at risk of blindness $(1,2)$. The treatment of DR is based on the control of blood glucose, blood pressure, and blood lipids, which can prevent further deterioration of retinopathy, and on this basis, better efficacy can be obtained by giving drug therapy to control local inflammation of the eyeball (3). Calcium dobesilate is a commonly used DR prevention and treatment drug, which can reduce blood viscosity, inhibit platelet aggregation, improve local microcirculation, and prevent and treat retinal edema and capillary hemorrhage. However, some studies (4) concluded that it was not different from placebo in improving macular edema. The Compound Danshen Dripping Pills are traditional Chinese medicine, consisting of Salvia miltiorrhiza, Panax notoginseng, borneol, and other medicinal compounds, which can improve local blood circulation, protect vascular endothelial cells, and achieve the purpose of eliminating congestion $(5,6)$. In China, Compound Danshen Dripping Pills have been widely used in the treatment of DR, but there is a lack of systematic review of reports on this topic. Meta-analysis was conducted in this study to search and collect randomized controlled trials (RCTs) over the past 10 years to understand the therapeutic effect of Compound Danshen Dripping Pills on DR. We present the following article in accordance with the PRISMA reporting checklist (available at https://dx.doi. org/10.21037/apm-21-2563).

\section{Methods}

\section{Databases and search strategy}

With the keywords "Compound Danshen Dripping Pills" or "danshen traditional chinese herbal medicine" or "danshen" or "chinese herbal" AND ("diabetic retinopathy" or "diabetic eye diseases"), literature published in the Chinese Medical Literature Database (CBM), Embase, Pubmed, and Medline from January 2010 to August 2021 were searched. Documents that were not RCTs were filtered out by the filters in each database.

\section{Inclusion criteria of literature}

(I) Study subjects: all patients were definitely diagnosed with DR; (II) all patients were given basic treatment for blood glucose control. On this basis, the patients in the intervention group were treated with Compound Danshen Dripping Pills combined with western medicine (calcium dobesilate, Qianlieqi injection) as the main intervention measures, while the patients in the control group were treated with western medicine (placebo) only. The intervention time was at least 8 weeks; (III) at least 1 ocular treatment index was included; (IV) complete data could be obtained from the literature for meta-analysis.

\section{Exclusion criteria of literature}

(I) Intervention subjects were non-DR patients (cataract, glaucoma, optic neuritic retinopathy); (II) intervention subjects were non-human (animal experiment); (III) intervention methods were mixed with other Traditional Chinese Medicine (TCM) or other intervention methods (laser therapy, hyperbaric oxygen therapy, acupuncture, intravenous drip), or there was no clear intervention time, administration frequency, or observation time; (IV) lack of treatment indicators, or data could not be transformed and used; (V) non-randomized controlled study.

\section{Literature screening}

Two researchers performed the database search to screen for literature. EndNote X9 was used to list all retrieved literature, the titles and abstracts of the literature were read, and articles with the same author and the same trial content were eliminated. According to the inclusion and exclusion criteria, after eliminating articles with unqualified study subjects, unqualified intervention methods, and unqualified study types, the full texts were read and articles without indicators were eliminated.

\section{Literature risk of bias assessment}

The Cocbrane Handbook for Systematic Reviews of Interventions (7) was used to evaluate the following six aspects of randomized controlled studies: (I) random allocation method; (II) blinding method; (III) implementation of allocation concealment; (IV) data integrity; (V) selective reporting bias; (VI) other biases. The risk of bias was evaluated as "low risk", "unclear", or "high risk". Two researchers independently completed the risk of bias assessment, and in the case of inconsistent results, a third person was invited to join the discussion to reach a consensus. 


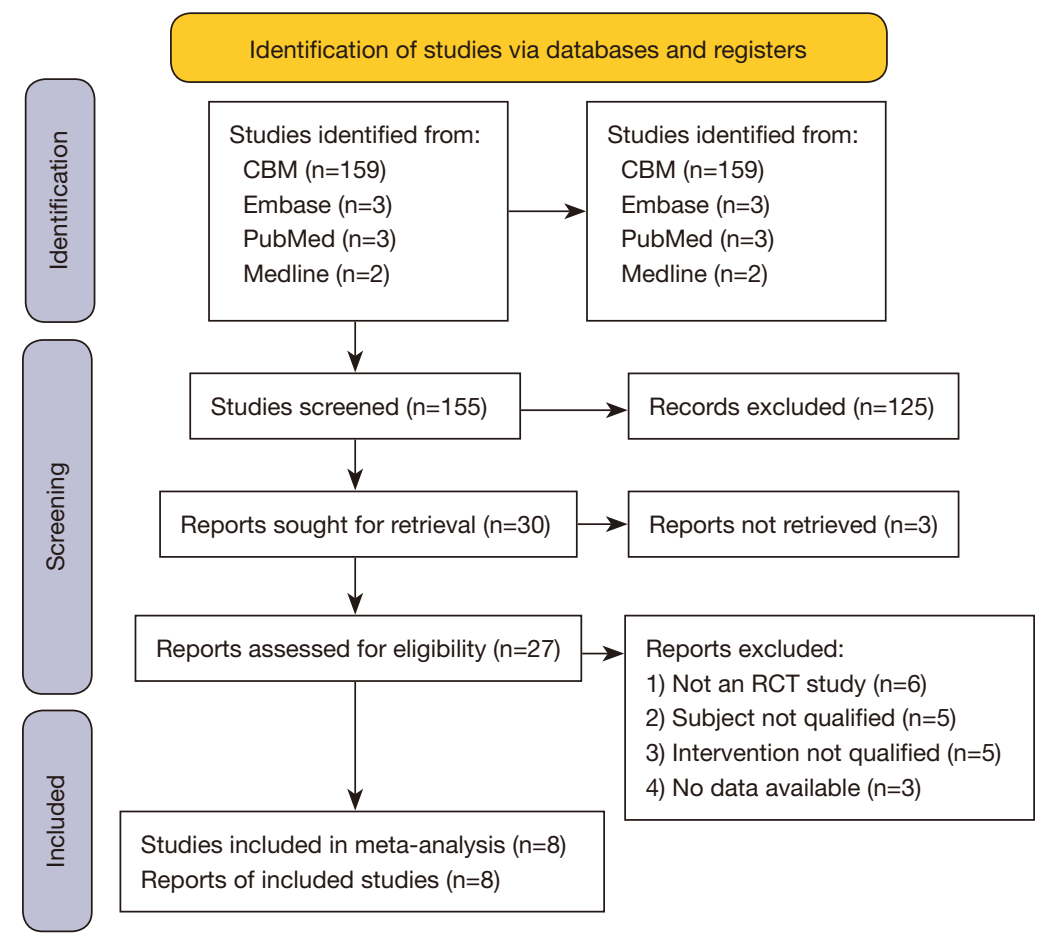

Figure 1 Literature search and inclusion flowchart.

\section{Outcome measures}

Rehabilitation indicators after treatment of DR included: (I) effective rate; (II) visual field gray value; (III) hemangioma volume; (IV) hemorrhagic plaque area; (V) visual acuity; (VI) blood pressure; (VII) serum cholesterol level; (VIII) incidence of adverse events; (IX) number of hemangiomas.

\section{Data extraction}

Two researchers read the full texts of the included studies one by one after evaluating the risk of bias and extracted the following data: author, publication time, number of grouped cases, age, gender ratio, intervention measures, intervention frequency, observation time, and outcome indicators. Data with number of cases shown as \% were converted to actual number of cases.

\section{Statistical analysis}

Meta-analysis was performed using Revman 5.4, a metaanalysis software provided by the Cochrane Collaboration. Continuous variables were statistically analyzed by inverse variance, using mean difference (MD) and 95\% confidence interval (CI) to report statistics. Discrete variables were reported using the odds ratio $(\mathrm{OR})$ and $95 \% \mathrm{CI}$, and $\mathrm{P}<0.05$ was considered to be statistically significant. If outcome measures had less than 3 studies, they were not included in the analysis. Forest plot descriptive statistics were used for comparisons. Literature heterogeneity was assessed by $\mathrm{I}^{2}$ analysis and the $\mathrm{Q}$ test, where $\mathrm{I}^{2}>50 \%$ or $\mathrm{P}<0.1$ indicated heterogeneity in the results. The random effects model was used to obtain OR values, otherwise the fixed effects model was used to obtain OR values. If heterogeneity between studies was suggested, the case-by-case exclusion method was used for investigation, descriptive analysis was given if the source of heterogeneity could not be identified. If the results of random effects model and fixed effects model were consistent, we considered the sensitivity of the analysis was stable. A funnel plot was used to indicate publication bias, but more than 10 included studies were required.

\section{Results}

\section{Literature screening process and results}

In this study, 167 documents were preliminarily searched, and 8 studies were included in the quantitative analysis after screening. The number of cases was 524. The literature search and screening process is shown in Figure 1. 


\section{Basic characteristics of the literature}

There were 524 patients included in this study, aged between 30 and 87 years, as shown in Table 1 .

\section{Literature bias assessment}

In this meta-analysis, only 1 study (9) indicated odd and even randomization, while the rest of the literature did not specify this. All literature described allocation concealment and blinding method implementation, 2 studies $(11,12)$ indicated no drop-out cases during data collection, while other studies did not provide this information. There was no selective reporting bias, while other bias is shown in Table 2 .

\section{Meta-analysis results}

\section{Therapeutic utility}

Of the 8 included studies, a total of 6 studies $(8-10,12,13,15)$ reported the therapeutic utility of Compound Danshen Dripping Pills, including 239 subjects in the treatment group and 237 in the control group, with no statistical heterogeneity of the studies $\left(\mathrm{I}^{2}=0 \%, \mathrm{P}=0.84\right)$. The pooled OR value of the 6 studies was 5.00, 95\% CI: $2.84,8.82$, with statistical significance $(\mathrm{P}<0.00001)$, indicating that the Compound Danshen Dripping Pills had a significant therapeutic effect, as shown in Figure 2.

\section{Visual field gray values}

A total of 4 studies $(8,9,13,15)$ reported visual field gray values after treatment, and there was no statistical heterogeneity in the studies $\left(\mathrm{I}^{2}=0 \%, \mathrm{P}=0.51\right)$. Using the fixed effects model for combined analysis, the total statistical value of the 4 studies was $\mathrm{MD}=-0.93,95 \% \mathrm{CI}$ : -0.98 , $-0.89, \mathrm{P}<0.00001$, with statistical significance, indicating that the Compound Danshen Dripping Pills could improve visual field gray values in DR patients, as shown in Figure 3.

\section{Hemangioma volume}

The improvement effect of the Compound Danshen Dripping Pills on hemangioma volume was reported in 3 studies $(8,9,13)$, and there was no statistical heterogeneity in the literature $\left(\mathrm{I}^{2}=0 \%, \mathrm{P}=0.72\right)$. The fixed effects model was used for combined analysis, and the combined statistical value of the 3 studies was $\mathrm{MD}=-3.16,95 \% \mathrm{CI}:-3.48,-2.84$, $\mathrm{P}<0.00001$, indicating that the hemangioma volume in the intervention group was smaller than that in the control group after treatment, and the Compound Danshen Dripping
Pills could improve the hemangioma volume in DR patients, as shown in Figure 4.

\section{Hemorrhagic plaque area}

A total of 6 studies $(8,9,11-13,15)$ reported the improvement effect of the Compound Danshen Dripping Pills on hemorrhagic plaque area, and the studies showed statistical heterogeneity $\left(\mathrm{I}^{2}=93 \%, \mathrm{P}<0.00001\right)$. The source of heterogeneity might be related to the differences in the characteristics of the included patients and intervention methods. As the specific source could not be found, a random effects model was used for combined analysis, and the combined statistical value of the 6 studies was MD $=-0.65,95 \%$ CI: $-0.97,-0.32, \mathrm{P}<0.0001$, indicating that the Compound Danshen Dripping Pills helped to reduce hemorrhagic plaque area after treatment, as shown in Figure 5 .

\section{Visual acuity}

A total of 3 studies $(8,13,15)$ reported the improvement effect of the Compound Danshen Dripping Pills on visual acuity, and the literature showed statistical homogeneity $\left(\mathrm{I}^{2}=0 \%, \mathrm{P}=0.93\right)$. The fixed effects model was used for combined analysis, and the combined statistical value of the 3 studies was $\mathrm{MD}=0.15,95 \%$ CI: $0.10,0.19, \mathrm{P}<0.00001$, as shown in Figure 6.

\section{Adverse reactions}

Only two literature $(9,13)$ reported adverse reactions, so there was no synthesis for this. Both of the two studies reported that the patients had no big adverse drug reactions after treatment, and there was no significant change in liver and kidney function and coagulation indicators before and after treatment.

\section{Sensitivity analysis}

For the analyses which showed no statistical heterogeneity, random effects model was performed to compare to the result of fixed effects model, all the results were nearly the same, which meant that the analyses were stable.

\section{Publication bias analysis}

The funnel plot showed uneven distribution of the studies, which meant there might be publication bias, as shown in Figure 7.

\section{Discussion}

Diabetic retinopathy is a high specific chronic complication 
Table 1 Basic characteristics, intervention measures, and rehabilitation indicators of the included literature

\begin{tabular}{|c|c|c|c|c|c|c|c|}
\hline Author name & Grouping & $\begin{array}{l}\text { Number of } \\
\text { subjects }\end{array}$ & $\begin{array}{l}\text { Sex } \\
\text { ratio }\end{array}$ & Age (years) & Interventions & $\begin{array}{l}\text { Intervention } \\
\text { time }\end{array}$ & $\begin{array}{l}\text { Rehabilitation } \\
\text { index }\end{array}$ \\
\hline \multirow[t]{2}{*}{$\begin{array}{l}\text { Huang et al. } \\
\text { (8) } 2020\end{array}$} & $\begin{array}{l}\text { Experimental } \\
\text { group }\end{array}$ & 20 & $9: 11$ & $53.16 \pm 2.16$ & $\begin{array}{l}\text { Oral Danshen dripping pills } 10 \text { pills/time, } \\
3 \text { times/d + oral calcium dobesilate } \\
500 \mathrm{mg} / \text { time, } 3 \text { times a day }\end{array}$ & 4 months & (a) (b) (c) (d) (e) \\
\hline & $\begin{array}{l}\text { Conventional } \\
\text { group }\end{array}$ & 20 & $10: 10$ & $52.16 \pm 2.46$ & Calcium dobesilate $500 \mathrm{mg} /$ time, tid, po & & \\
\hline $\begin{array}{l}\text { Ruan et al. (9) } \\
2017\end{array}$ & $\begin{array}{l}\text { Conventional } \\
\text { group }\end{array}$ & 35 & $20: 15$ & $52.70 \pm 1.70$ & Calcium dobesilate $500 \mathrm{mg} /$ time, tid, po & & \\
\hline \multirow[t]{2}{*}{$\begin{array}{l}\text { Chen et al. } \\
\text { (11) } 2019\end{array}$} & $\begin{array}{l}\text { Experimental } \\
\text { group }\end{array}$ & 41 & $21: 20$ & $54.6 \pm 5.01$ & $\begin{array}{l}\text { Oral Danshen dripping pills } 10 \text { pills/time, } \\
3 \text { times/d + Qianlieqin injection }\end{array}$ & 8 weeks & (d) (i) \\
\hline & $\begin{array}{l}\text { Conventional } \\
\text { group }\end{array}$ & 41 & $20: 21$ & $52.4 \pm 5.3$ & $\begin{array}{l}\text { Qianlie injection, } 10 \mu \mathrm{g} \text { dissolved in } 20 \mathrm{~mL} \\
\text { normal saline, intravenous injection, once } \\
\text { a day }\end{array}$ & & \\
\hline \multirow[t]{2}{*}{$\begin{array}{l}\text { He et al. (12) } \\
2013\end{array}$} & $\begin{array}{l}\text { Experimental } \\
\text { group }\end{array}$ & 42 & $22: 20$ & $58.2 \pm 9.80$ & $\begin{array}{l}\text { Oral Danshen dripping pills } 10 \text { pills/time, } \\
3 \text { times/d }\end{array}$ & 2 months & (a) (d) (i) \\
\hline & $\begin{array}{l}\text { Conventional } \\
\text { group }\end{array}$ & 42 & $26: 16$ & $54.3 \pm 12.30$ & Placebo, bid & & \\
\hline \multirow[t]{2}{*}{$\begin{array}{l}\text { Zhao et al. } \\
\text { (14) } 2014\end{array}$} & $\begin{array}{l}\text { Experimental } \\
\text { group }\end{array}$ & 34 & $18: 16$ & $54.3[39-70]$ & $\begin{array}{l}\text { Danshen dripping pills } 10 \text { pills/time, } \\
3 \text { times/d }\end{array}$ & 3 months & (a) \\
\hline & $\begin{array}{l}\text { Conventional } \\
\text { group }\end{array}$ & 38 & $20: 18$ & $53.5[40-68]$ & Placebo, bid & & \\
\hline \multirow[t]{2}{*}{$\begin{array}{l}\text { Liu et al. (15) } \\
2011\end{array}$} & $\begin{array}{l}\text { Experimental } \\
\text { group }\end{array}$ & 26 & - & - & $\begin{array}{l}\text { Oral Danshen dripping pills } 10 \text { pills/time, } \\
3 \text { times/d }\end{array}$ & 3 months & (b) (d) (e) (i) \\
\hline & $\begin{array}{c}\text { Conventional } \\
\text { group }\end{array}$ & 26 & - & - & $\begin{array}{l}\text { Placebo: vitamin } \mathrm{B} 1 \text { tablets, } 20 \mathrm{mg} / \mathrm{time} \text {, } \\
\text { vitamin } \mathrm{C} \text { tablets } 0.2 / \text { time, inosine tablets } \\
0.2 \mathrm{~g} / \text { time, } 3 \text { times a day }\end{array}$ & & \\
\hline
\end{tabular}

Rehabilitation indexes were (a) effective rate; (b) visual field gray value; (c) hemangioma volume; (d) hemorrhagic plaque area; (e) visual acuity; (f) blood pressure; (g) serum cholesterol level; (h) incidence of adverse events; (i) number of hemangiomas.

caused by diabetes, its treatment base on good blood sugar management, blood pressure management and blood lipid regulation (16). Vascular endothelial growth factor (VEGF) is involved in the pathogenesis of diabetic macular edema, Anti VEGF drugs can prevent the excessive expression of this factor in the serum, prevent vascular proliferation, reduce 
Table 2 Risk of bias assessment based on the Cochrane Collaboration criteria

\begin{tabular}{|c|c|c|c|c|c|c|}
\hline Study & $\begin{array}{c}\text { Random sequence } \\
\text { generation }\end{array}$ & $\begin{array}{l}\text { Allocation } \\
\text { concealment }\end{array}$ & $\begin{array}{l}\text { Blinding } \\
\text { method }\end{array}$ & Data integrity & $\begin{array}{l}\text { Selective } \\
\text { reporting }\end{array}$ & Other bias \\
\hline Huang et al. (8) 2020 & Unclear & Unclear & Unclear & Unclear & Low & Unclear \\
\hline Ruan et al. (9) 2017 & Low & Unclear & Unclear & Unclear & Low & Unclear \\
\hline Xie et al. (10) 2017 & Unclear & Unclear & Unclear & Unclear & Low & Unclear \\
\hline Bai et al. (13) 2017 & Unclear & Unclear & Unclear & Unclear & Low & Unclear \\
\hline Zhao et al. (14) 2014 & Unclear & Unclear & Unclear & Unclear & Low & Unclear \\
\hline Liu et al. (15) 2011 & Unclear & Unclear & Unclear & Unclear & Low & Unclear \\
\hline
\end{tabular}

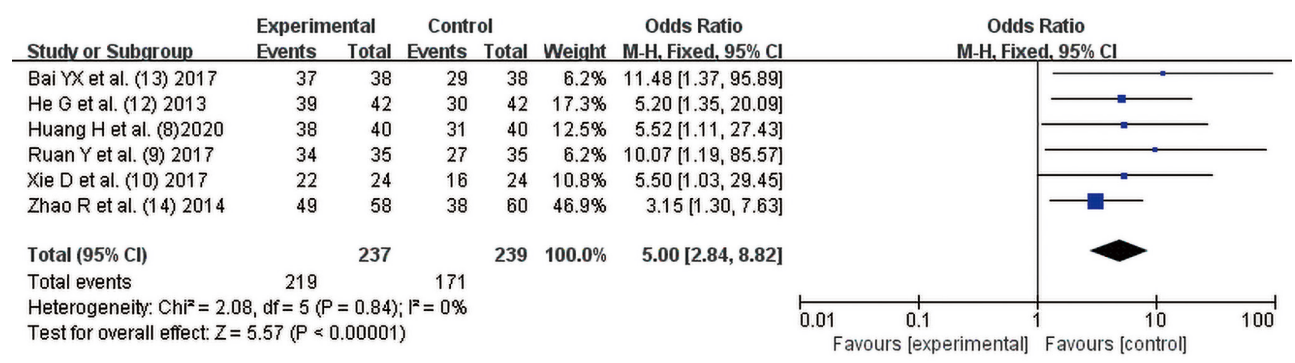

Figure 2 Forest plot of the therapeutic effect of the Compound Danshen Dripping Pills.

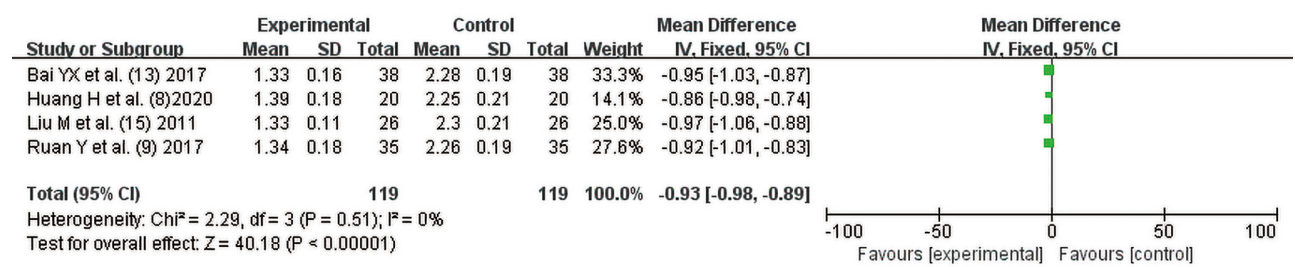

Figure 3 Forest plot of improvement in visual field gray values by the Compound Danshen Dripping Pills.

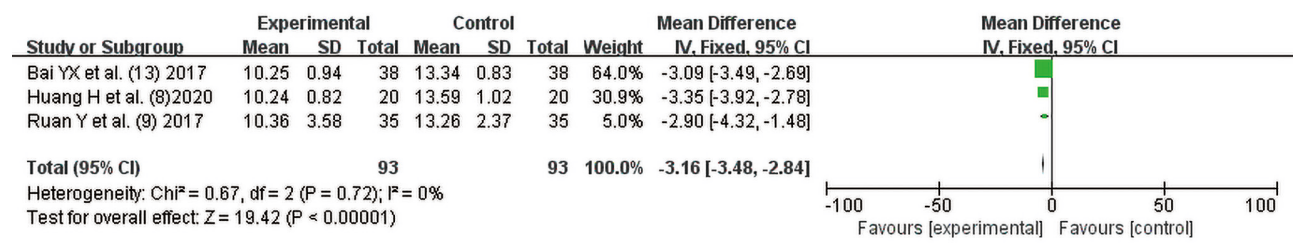

Figure 4 Forest plot of the effect of the Compound Danshen Dripping Pills on reducing the volume of hemangiomas.

macular edema and improve vision (17). Glucocorticoid has the functions of anti-inflammatory, anti-angiogenesis and stabilizing retinal barrier, in addition, some drugs that improve microvascular circulation (such as calcium dobesilate) can regulate capillary permeability and flexibility, inhibit platelet aggregation and reduce blood viscosity, 


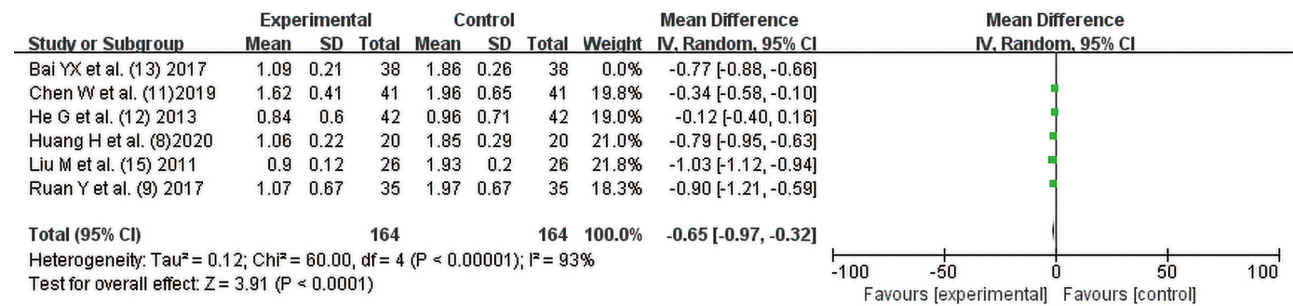

Figure 5 Forest plot of the effect of the Compound Danshen Dripping Pills on reducing hemorrhagic plaque area.

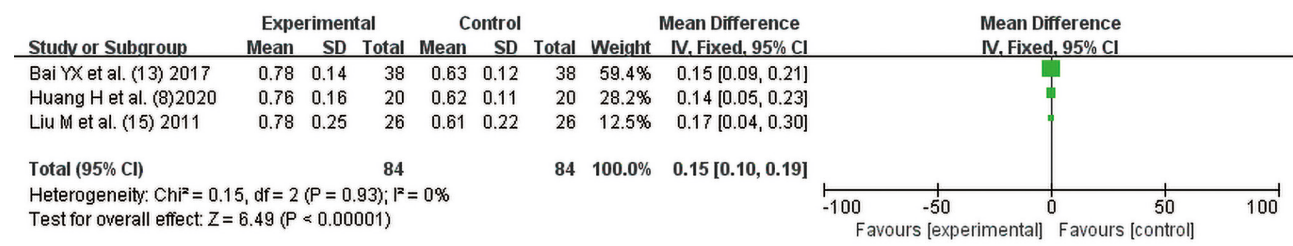

Figure 6 Forest plot of the improvement effect of the Compound Danshen Dripping Pills on visual acuity.

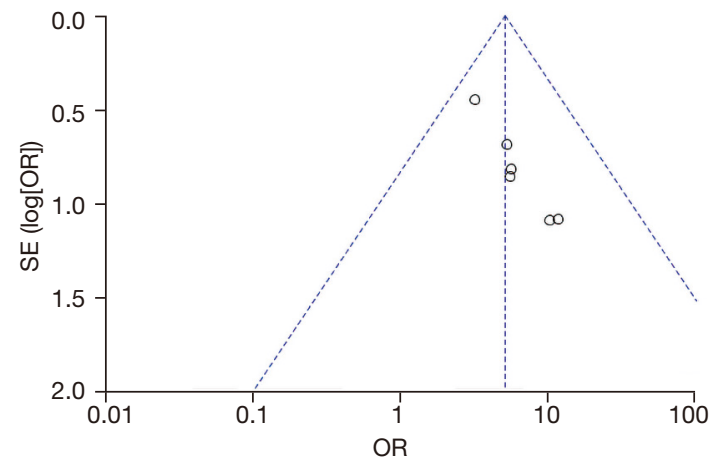

Figure 7 Funnel plot of the therapeutic effect of the Compound Danshen Dripping Pills.

which has been proved to improve diabetic retinopathy (18). In recent years, Chinese medicine has gradually been involved in the treatment of diabetic retinopathy, combined with conventional western medicine, to reduce vascular endothelial damage and improve vascular microcirculation, so as to achieve good therapeutic effect (19).

A total of 8 studies were included in this meta-analysis. There was little difference in sample size between the studies. The minimum number of cases was 40 and the maximum number of cases was 84 . In terms of therapeutic drugs, all studies mentioned that the intervention was performed on the basis of effective control of blood glucose, and the combination of traditional Chinese and western medicine was mainly through oral Compound Danshen
Dripping Pills + oral calcium dobesilate (or injection of Qianlieqi). Some studies $(10,11,14)$ did not mention which western medicine was applied, and the control group was given oral calcium dobesilate or placebo. Metaanalysis showed that the effectiveness of the Compound Danshen Dripping Pills combined with western medicine in the treatment of DR was higher than that of western medicine (or placebo) alone, and could effectively reduce the visual field gray value, reduce the hemangioma volume and hemorrhagic plaque area, and improve visual acuity. $\mathrm{DR}$ is a microangiopathy formed by a combination of factors, characterized by thrombocytosis, enhanced platelet aggregation, increased blood viscosity, and vascular endothelial damage. DR is considered as a stasis phenomenon in TCM, while Compound Danshen Dripping Pills can remove microvascular obstruction, and improve local microcirculation (20). the Compound Danshen Dripping Pills are produced based on TCM theory combined with modern biotechnology, and the main components are Salvia miltiorrhiza, Panax notoginseng, and borneol. They are characterized by small dosage, rapid absorption, and rapid onset of action, and can rapidly achieve the effects of cooling the blood, hemostasis, eliminating stasis, and dispersing pain after oral administration $(21,22)$.

In a meta-analysis conducted by Huang et al. (23) in 2017 there were 13 RCTs identified, the conclusion was that $C D D P s$ were both safe and efficacious for treating DR, it improved vision by measuring the outcomes of 
microaneurysms, hemorrhage, exudate, vision, and fundus fluorescein angiography. Our study showed CDDPs are efficacious and safe too for treating DR, the results were consistent with the previous meta-analysis, but by measuring different outcomes of therapeutic effectiveness, visual field gray value, the hemangioma volume, hemorrhagic plaque area, and the visual acuity.

In this study, during the analysis of individual indicators (hemorrhagic plaque area), it was found that there was significant heterogeneity among the literature, which may be explained by the following aspects. Firstly, the study did not distinguish the duration of diabetes, DR severity grade, and whether the cases were accompanied by other complications, which were the influencing factors of the outcome indicators. Secondly, the intervention process was not uniform. In the 8 studies included in this metaanalysis, the intervention method was integrated traditional Chinese and western medicine, but there were differences between the Compound Danshen Dripping Pills and the integrated western medicine. Some literature included oral calcium dobesilate, others included injection of Qianlie, while western medicine was not mentioned in some studies. Thirdly, the non-uniform intervention method in the control group (western medicine or placebo) might have caused heterogeneity. It was also found in the meta-analysis that the languages of all 8 included studies were Chinese and there were still few studies from other countries. All the reports had problems such as unclear random allocation method, unclear allocation concealment, and unclear blinding method, and dropping out cases were not mentioned in all articles, which reduced the strength of evidence. In future studies, more double-blind clinical trials still need to be included to ensure the credibility of the conclusions.

\section{Conclusions}

The Compound Danshen Dripping Pills combined with western medicine have good efficacy and safety in the treatment of DR. However, due to the low quality of the included literature, the evidence is not sufficient, and more high-quality randomized controlled studies are needed in clinical practice to provide stronger evidence.

\section{Acknowledgments}

Funding: None.

\section{Footnote}

Reporting Checklist: The authors have completed the PRISMA reporting checklist. Available at https://dx.doi. org/10.21037/apm-21-2563

Conflicts of Interest: All authors have completed the ICMJE uniform disclosure form (available at https://dx.doi. org/10.21037/apm-21-2563). The authors have no conflicts of interest to declare.

Ethical Statement: The authors are accountable for all aspects of the work in ensuring that questions related to the accuracy or integrity of any part of the work are appropriately investigated and resolved.

Open Access Statement: This is an Open Access article distributed in accordance with the Creative Commons Attribution-NonCommercial-NoDerivs 4.0 International License (CC BY-NC-ND 4.0), which permits the noncommercial replication and distribution of the article with the strict proviso that no changes or edits are made and the original work is properly cited (including links to both the formal publication through the relevant DOI and the license). See: https://creativecommons.org/licenses/by-nc-nd/4.0/.

\section{References}

1. Lechner J, O'Leary OE, Stitt AW. The pathology associated with diabetic retinopathy. Vision Res 2017;139:7-14.

2. Heng LZ, Comyn O, Peto T, et al. Diabetic retinopathy: pathogenesis, clinical grading, management and future developments. Diabet Med 2013;30:640-50.

3. Wilkinson CP, Ferris FL 3rd, Klein RE, et al. Proposed international clinical diabetic retinopathy and diabetic macular edema disease severity scales. Ophthalmology 2003;110:1677-82.

4. Ribeiro ML, Seres AI, Carneiro AM, et al. Effect of calcium dobesilate on progression of early diabetic retinopathy: a randomised double-blind study. Graefes Arch Clin Exp Ophthalmol 2006;244:1591-600.

5. Luo D, Qin Y, Yuan W, et al. Compound Danshen Dripping Pill for Treating Early Diabetic Retinopathy: A Randomized, Double-Dummy, Double-Blind Study. Evid Based Complement Alternat Med 2015;2015:539185.

6. Singh S, Kushwaha P, Gupta SK. Exploring the Potential of Traditional Herbs in the Management of 
Diabetic Retinopathy: An Overview. Drug Res (Stuttg) 2020;70:298-309.

7. Cumpston M, Li T, Page MJ, et al. Updated guidance for trusted systematic reviews: a new edition of the Cochrane Handbook for Systematic Reviews of Interventions. Cochrane Database Syst Rev 2019;10:ED000142.

8. Huang H. Effect analysis of Danshen Dripping Pills in adjuvant treatment of diabetic retinopathy. Northern Medicine 2020;17:100-1.

9. Ruan Y, Chen M, Liu Z, et al. Clinical study of compound oral Danshen dripping pills combined with calcium dobesilate in the treatment of diabetic retinopathy. Chinese Journal of South Medical Science 2017;45:18-20, 23.

10. Xie D, Qiu P, Li W. Effect of Compound Danshen Dripping Pills on the treatment of non proliferative diabetic retinopathy. Modern Diagnosis and Treatment 2017;28:2585-6.

11. Chen W. Compound Danshen dripping pills combined with alprostadil in the treatment of early diabetic retinopathy. Bethune Medical Journal 2019;17:464-5.

12. He G, Zhen D. Clinical observation of Compound Danshen Dripping Pills in treating non-proliferative diabetic retinopathy. Journal of Lanzhou University (Medical Science) 2013;39:76-8.

13. Bai YX. Effect of calcium dobesilate combined with Compound Danshen Dripping Pills on diabetic retinopathy and its influence on serum inflammatory factors. Journal of Qiqihar Medical School 2017;38:2641-3.

14. Zhao R, Jin L, Li M, et al. Clinical observation on hyperbaric oxygen combined with Compound Danshen Dripping Pills in treatment of early diabetic retinopathy in type 2 diabetes mellitus. Journal of Qiqihar Medical School 2014;35:3624-5.

Cite this article as: Huang H, Li Y, Huang Q, Lei R, Zou W, Zheng Y. Efficacy of Compound Danshen Dripping Pills combined with western medicine in the treatment of diabetic retinopathy: a systematic review and meta-analysis of randomized controlled trials. Ann Palliat Med 2021;10(10):10954-10962. doi: 10.21037/ apm-21-2563
15. Liu M, Hao J. Clinical observation of Compound Danshen Dripping Pills in treating early diabetic retinopathy. China Community Doctor 2011;27:17.

16. Kollias AN, Ulbig MW. Diabetic retinopathy: Early diagnosis and effective treatment. Dtsch Arztebl Int 2010;107:75-83; quiz 84.

17. Bolinger MT, Antonetti DA. Moving Past Anti-VEGF: Novel Therapies for Treating Diabetic Retinopathy. Int J Mol Sci 2016;17:1498.

18. Zhang X, Liu W, Wu S, et al. Calcium dobesilate for diabetic retinopathy: a systematic review and metaanalysis. Sci China Life Sci 2015;58:101-7.

19. Pang B, Li QW, Qin YL, et al. Traditional Chinese medicine for diabetic retinopathy: A systematic review and meta-analysis. Medicine (Baltimore) 2020;99:e19102.

20. Lian F, Wu L, Tian J, et al. The effectiveness and safety of a danshen-containing Chinese herbal medicine for diabetic retinopathy: a randomized, double-blind, placebocontrolled multicenter clinical trial. J Ethnopharmacol 2015;164:71-7.

21. Nie X, Wang B, Hu R, et al. Development and Evaluation of Controlled and Simultaneous Release of Compound Danshen Based on a Novel Colon-Specific Osmotic Pump Capsule. AAPS PharmSciTech 2020;21:38.

22. MEIm XD, Cao YF, Che YY, et al. Danshen: a phytochemical and pharmacological overview. Chin J Nat Med 2019;17:59-80.

23. Huang W, Bao Q, Jin D, et al. Compound Danshen Dripping Pill for Treating Nonproliferative Diabetic Retinopathy: A Meta-Analysis of 13 Randomized Controlled Trials. Evid Based Complement Alternat Med 2017;2017:4848076.

(English Language Editor: C. Betlazar-Maseh) 